\title{
Research on Creative Education, Integration of Industry and Education in the Application Talents Cultivation
}

\author{
Jianefeng HU \\ Jiangxi University of Technology, 330098 Nanchang, China \\ huguess@qq.com
}

Keyword: Creative Education; Integration of Industry and Education; Application talents cultivation; local college and university

\begin{abstract}
Training application talents is the primary mission and the fundamental task of the local college and university. Deepen the reform of creative education in local college and university is a breakthrough point of the comprehensive reform of higher education. Integration of industry and education in college and university is an inevitable approach to cultivate application talents. This paper puts forward some thinking about the cultivation of application talents in local college and university from two perspectives: creative education, integration of industry and education.
\end{abstract}

\section{Introduction}

Cultivating application talents is the primary mission and basic task of local colleges and universities. Local colleges and universities must highlight the characteristics of "local", take the initiative to integrate into the local economic and social development needs, broaden the space for colleges and universities, in order to achieve the sustainable development of local colleges and universities. The relationship between higher education and economic social development has three kind of realm. The first is the active service, the second is comprehensive support, the third is leading innovation.

Deepening the reform of creative and entrepreneurship education is the urgent need to accelerate the implementation of the innovation drive development strategy, is a breakthrough point to push forward the comprehensive reform of higher education, is great significance to promote graduates more high quality employment. To firmly establish the advanced concepts of creative education, and to strive to integrate creative education and professional education, to transform from imparting knowledge to focus on the spirit of creative and creative ability training, so as to effectively enhance the students' creative spirit and creative ability and improve higher education's contribution to the society and the livelihood of the people.

To firmly grasp the integration of industry and education, school enterprise cooperation, unswervingly to break the development chain of school seal and self-evaluation, to integrate school management and personnel training to the link fusion in industry chain, public service chain and value creation chain. Currently emerging strategic industry is defined at a particular stage of economic development, with major breakthroughs in science and technology as the premise, based on depth fusion of new technology and new industry, will cause new social needs, drives the adjustment of industrial structure and the transformation of the mode of economic development, and 
in a period of growth has a significant influence on the leading industry, leading industry or pillar industry of industries and sectors on the comprehensive national strength and social progress. Emerging strategic industry has the following characteristics: strategic, emerging, industrial, breakthrough, long-term growth and risk.

\section{Adhere to the position of application oriented university}

Colleges and universities should focus on cultivating application talents, servicing for the local development, basing on teaching practice, carrying out applied research, and must adhere to the six principles: the orientation target remains unchanged, the school running idea remains unchanged, servicing for local development remains unchanged; teaching ideas and methods should be reformed, major structure and curriculum system should be reformed, the talents training mode should be reformed.

(1) To promote the transformation and upgrade of the industry oriented, top level design of high-quality application talents training should be written into the school's new development plan. The college and university should train the application talents in every part of the school work. The leadership of the school should be familiar with the application talents training, and the middle management personnel should cultivate the application talents.

(2) To accelerate the strategic cooperation between school and enterprise, college and university make full useful of regional advantages, accelerate the strategic cooperation with international high level University of Applied Science and technology, leading enterprises, construct new industrial technology institute and relatively independent secondary college, and introduce international teachers and school management mode.

(3) To enhance the professional matching degree further with docking industry, school should make the advantage of the characteristics of professional concentration and in-depth docking local emerging strategic industry support system, enhance the matching degree among major construction, local development and industry transformation.

(4) To introduce good professional assessment and international professional certification, In order to construct brand majors. School should adjust the majors, based on school resources, meet the need of society. Based major clusters, school should gradually improve the concentration of professional features of majors. School should begin major assessment, international major certification and brand major construction.

(5) To further strengthen the cooperative education mechanism for the government and industry.

(6) To build the dual teacher's evaluation and incentive mechanism and the industrialization result oriented policy.

(7) To fully implement the effective teaching system. The education in college and university should take the students as the basis, and the reform and development of school should take the teachers as the basis, and the core of the school management is person-oriented. School should establish the students' main position in the education teaching, focus on cultivating students' practical ability and innovation ability, and establish a new student management concept. School must establish comprehensive education idea of "student oriented" and "teacher oriented". 


\section{Thinking of application talents training}

(1) To construct new strategic industry professional cluster and concise subject direction. School should take the dislocation development, play its own advantage of near-ind ustry features. Aiming at the real needs of local industry development, school should take differentiation development and characteristic development. Major group should depth dock industry chain. Cultivation system of school must be application technology training system combining talent specification and practicing certification and the.

(2) To integrate content of project into curriculum module and course teaching, including general education, discipline foundation, professional skills and other curriculum modules. The application technology curriculum system should melt the knowledge, the ability, the quality coordinated development. To build course system of "platform + module + business", school rely on general education curriculum platform and major basic courses platform, develop professional curriculum modules and project training module courses. School rely on enterprise production and research equipment, and enterprises technical backbone, build part of the professional course forward to the enterprise commenced and organization at the scene of teaching. School make full use of the large-scale cooperation enterprise resource advantages, and construct campus production training base, increase the proportion of professional practice direction of elective courses proportion and the frontier lecture classes. School should develop characteristic courses, including characteristic practice lesson, innovation and entrepreneurship course and relevant professional qualification certificate content and other courses, and create conditions to guide and encourage students to research. Teaching practice includes three aspects of foundation courses, professional courses and comprehensive courses; includes seven modules of basic experiment module, design module, vocational skills module, position practice module, professional experiment module, comprehensive experiment module and practice training module.

(3) To strengthen the construction of the teachers team in the double qualification. There are two keys of near industry and internationalization, two themes of teacher development and improving teacher ability, seven projects of young teachers training project, near industry teacher training programs, internationalization promotion project, increasing ability and ethics project, assessment project, educational thought project and educational technology training project. School should emphasis on entrance selection of teachers, and practical ability is an important consideration, teachers should transfer from the enterprise or work in the enterprise for more than 3 years. School should strengthen the training of teachers, fresh teachers must bear the teaching experiment and work in the enterprise.

(4) To reconstruct application talents training mode. Talents training focus on four kind of experience of foreign travel experience (expanding the field of vision), the second campus experience (enjoying high-quality resources; perception of exotic culture), social practice experience (liberal arts of self-cultivation, innovation and entrepreneurship experience (innovation and create entrepreneurial). Six joint mode for school enterprise cooperation can be operated, including joint selecting teachers, joint design training programs, joint formulating the standards of admission, joint implementation of enrollment plan, joint participation in the training process, and joint promoting the employment and entrepreneurship of students.

(5) To carry out innovation and entrepreneurship education, cultivate students' innovation and entrepreneurship ability. School take "College Innovation Park" as the carrier, establish innovation and entrepreneurship education system including academic competition, entrepreneurship and career 
development education, innovation and entrepreneurship training program and innovation and entrepreneurship research.

(6) To collaborate innovation for university research and cultivation of application talents. School strengthen the integration of local government, industry, research institute with depth, in order to form an application talents training mechanism of open, flexible, channel interoperability, diverse. School promote vigorously the depth of enterprise integration, and establish comprehensive strategic partnership with leading enterprises, form the same interests community. Taking the initiative into the industrial park of science and technology park, school build collaborative innovation education platform.

\section{Conclusions}

College and university pay attention to the education and guidance of the spirit of innovation, and integrate the creative ideas into the campus culture. Through improving the students' innovation ability and improving the teacher's innovation conscious ness, school implement the idea of creative education. School stimulate students' interest in innovation, cultivate innovative thinking, guide the innovative practice for the idea, and develop the innovative ability of students, through the spread of the theory of innovation knowledge, improving teachers' innovation consciousness, arousing teachers' creativity work enthusiasm, and creating teachers' innovative culture atmosphere and so as to improve the teacher's sense of innovation.

\section{Acknowledgment}

This work was supported by Jiangxi Province Office of Education of Humanities and Social Science Research [No. GL 1409]. And the project of Technology Department of Jiangxi Province [No 2013BBE50051] also gives us lots of help.The author thanks Dr. Hu Jian-feng for help.

\section{References}

[1] Yang J X, Song K H, Zhang J, et al. On Reform and Innovation of Talent-Cultivating Model in Local Universities_- In the Case of Trinitarian Reform Mode of Applied Talent Cultivation in Huaihua University[J]. Journal of Huaihua University, 2012.

[2] Long Q, Hu Q. Study on innovation talent cultivation of computer specialty in applied undergraduate universities[J]. Experimental Technology \& Management, 2010.

[3] Shi-Chun L I, Zhu X H, Ren-Qi H E, et al. Innovation Ability Comprehensive Quality Cultivation of Applied Talent in Newly-built University[J]. Value Engineering, 2013.

[4] Fan X C, Sun Y, Ren-Feng X U, et al. On the Talent Training Model of Applied Bachelor Talents of Computer Specialty Based on Collaborative Innovation[J]. Vocational \& Technical Education, 2013.

[5] Yu J, Ming X. Research on CDIO-based Mechanical Applied Engineering Talent Training Mode[J]. China Education Innovation Herald, 2013.

[6] Guo Q, Zhao M. Study on Innovation of Applied Talents Training Programs of Modern Service Industry Based on Core Skills[J]. Vocational \& Technical Education, 2010. 
[7] Cao G, Dai Y, Yao L. Discussion on the cultivation mode of engineering applied innovative talent in colleges and universities[J]. International Conference on Artificial Intelligence Management Science \& Electronic Commerce, 2011.

[8] Yun-Baoa X U, Chen H M. Research on Government-Industries-Colleges(Research Institutes) Collaborative Innovation Mechanism and Pattern for Local Applied Colleges[J]. Journal of Hunan Institute of Engineering, 2013.

[9] Zhang Y. Study on College Teaching Mode of Startups Education in Perspective of Innovation Ability[J]. Open Journal of Leadership, 2015.

[10]Zhao L Z, Liu J Q, Jiang S Y. Exploration of Innovation Center for College Students Based on Project Carrying and Collaborative Innovative Mode_- Taking Innovation Center for College Students of Shaoyang University Food Specialty as Example[J]. Journal of Anhui Agricultural Sciences, 2015. 